\title{
Utilização de um meio cromogênico e da técnica de semi-nested PCR para identificação de espécies de Candida
}

\author{
Use of chromogenic medium and semi-nested PCR-based assay to \\ identify Candida species
}

\author{
Narjara do Carmo Oliveira ${ }^{1}$; Rita de Cássia Pontello Rampazzo ${ }^{2}$; Mariana Caldas \\ Minari²; Paulo Roberto Ceridório Corrêa ${ }^{2}$; Fernando César Bizerra ${ }^{2}$; Marcelo \\ Carneiro $^{3}$; Terezinha Inez Estivalet Svidzinski ${ }^{4}$; Luciana Furlaneto Maia ${ }^{5}$; \\ Sueli Fumie Yamada-Ogatta
}

\section{Resumo}

\begin{abstract}
Nesse trabalho, o meio cromogênico CHROMagar Candida e a técnica de semi-nested PCR (sn-PCR) foram comparados quanto a sua capacidade de identificar a espécie de 52 isolados clínicos de Candida sp. Com o emprego do meio cromogênico, 39 (75\%) isolados foram identificados presuntivamente como C. albicans $(\mathrm{n}=22)$, . glabrata $(\mathrm{n}=9)$, C. tropicalis $(\mathrm{n}=5)$ e $C$. $k r u s e i(\mathrm{n}=3)$. Treze isolados $(25 \%)$ não puderam ser identificados. Por meio da técnica de sn-PCR, que se baseia na amplificação de uma região do cluster gênico do RNA ribossomal (5.8S - 28S), $43(83 \%)$ isolados foram identificados como $C$. albicans $(\mathrm{n}=24)$, C. glabrata $(\mathrm{n}=11)$, C. tropicalis $(\mathrm{n}=5), C$. parapsilosis $(\mathrm{n}=3)$ e nove isolados não puderam ser identificados em nível de espécie. Entre os 52 isolados analisados, $34(65,4 \%)$ apresentaram resultados concordantes pelos dois métodos, $12(23,1 \%)$ apresentaram resultados discrepantes, e 6 $(11,5 \%)$ não puderam ser identificadas por nenhuma das duas metodologias. Os resultados indicam que ambas as técnicas apresentam limitações, mas o método de sn-PCR é mais adequado que o meio cromogênico para a identificação de espécies do gênero Candida, devido ao menor número de isolados que não puderam ser identificados.
\end{abstract}

Palavras-chave: Candida sp. Identificação. Meio CHROMagar. Semi-nested-PCR.

\begin{abstract}
In this study, the chromogenic medium CHROMagar Candida ${ }^{\mathrm{TM}}$ and semi-nested PCR-based assay (snPCR) were compared in relation to their capacity to identify the species of 52 clinical isolates of Candida sp. By using the chromogenic medium, 39 (75\%) yeasts isolates were presumptively identified as $C$. albicans $(\mathrm{n}=22)$, C. glabrata $(\mathrm{n}=9)$, C. tropicalis $(\mathrm{n}=5)$ and $C$. krusei $(\mathrm{n}=3)$. Thirteen isolates $(25 \%)$

\footnotetext{
1 Mestre em Microbiologia pela Universidade Estadual de Londrina, Londrina- PR. Foi bolsista da Coordenação de Aperfeiçoamento de Pessoal de Nível Superior (CAPES). E-mail: narjaraoliveira@ yahoo.com.br.

2 Alunos do Programa de Pós-Graduação em Microbiologia (Nível: Mestrado). Departamento de Microbiologia, Centro de Ciências Biológicas, Universidade Estadual de Londrina, Londrina - Paraná.

3 Aluno do Programa de Pós-Graduação em Microbiologia (Nível: Mestrado). Departamento de Microbiologia, Centro de Ciências Biológicas, Universidade Estadual de Londrina, Londrina - Paraná. Serviço de Infectologia do Hospital Santa Cruz, Santa Cruz do Sul - Rio Grande do Sul.

${ }^{4}$ Departamento de Análises Clínicas, Centro de Ciências da Saúde, Universidade Estadual de Maringá, Maringá - Paraná.

5 Departamento de Microbiologia, Centro de Ciências Biológicas, Universidade Estadual de Londrina, Londrina - Paraná.
} 
were not distinguishable to the species level. Through the sn-PCR, that is based on the ribosomal RNA genes $(5.85-28 \mathrm{~S})$ cluster amplifications, $43(83 \%)$ isolates were identified as $C$. albicans $(\mathrm{n}=24), C$. glabrata $(\mathrm{n}=11)$, C. tropicalis $(\mathrm{n}=5)$, . parapsilosis $(\mathrm{n}=3)$ and nine isolates could not be identified to the species level. Among the 52 analyzed isolates, 34 (65.4\%) were in accordance with both methods, 12 $(23.1 \%)$ showed discrepant results, and $6(11.5 \%)$ could not be identified by any of the methodologies. The results indicate that both methods are limited, but the sn-PCR is more adequate than the chromogenic medium to identify species of the Candida genus, due to the lowest number of isolates that could not be identified. Key words: Candida sp. Identification. CHROMagar médium. Semi-nested PCR.

\section{Introdução}

Espécies do gênero Candida fazem parte da microbiota normal de superfícies mucosas do trato gastrointestinal e genital de animais, inclusive dos humanos. Entretanto, podem ser responsáveis por uma variedade de quadros clínicos, desde infecções superficiais de mucosa, como candidíase vulvovaginal e orofaríngea, até infecções sistêmicas principalmente quando fatores de risco estão presentes nos hospedeiros humanos. Esses fatores geralmente incluem: uso prolongado e indiscriminado de antimicrobianos de amplo espectro, uso de esteróides ou outras substâncias imunossupressoras, diabetes mellitus, AIDS e funções fagocitárias alteradas (WEIG; GROB; MUHLSCHLEGEL, 1998).

Como microrganismo oportunista, essas leveduras podem expressar vários fatores de virulência que contribuem para a patogênese da infecção. Entre esses fatores, encontram-se adesão às células e tecidos dos hospedeiros, secreção de enzimas hidrolíticas (proteases, fosfolipases e lipases), alteração fenotípica da morfologia celular e da colônia (switching fenotípico) e dimorfismo (CALDERONE; FONZI, 2001). Diferenças na expressão desses fatores têm sido descritas durante infecções em sítios anatômicos distintos (HUBE, 2004), bem como entre espécies diferentes (HAYNES, 2001).

As candidíases são usualmente tratadas com derivados poliênicos (anfotericina B) e imidazólicos (fluconazol, cetoconazol, itraconazol). Entretanto, relatos de isolados resistentes a essas substâncias surgiram rapidamente na literatura (PRICE; LaROCCO; GENTRY, 1994; MATHEMA et al., 2001; SANT'ANA et al., 2002; CANTÓN et al.,
2003; SANCHEZ-VARGAS et al., 2005). Além disso, as espécies de Candida apresentam sensibilidade variada aos novos antifúngicos em desenvolvimento (PFALLER et al., 1999).

A incidência de infecções causadas por Candida sp tem aumentado nas últimas décadas, particularmente entre pacientes hospitalizados e imunocomprometidos. Embora C. albicans seja a mais freqüentemente isolada de amostras clínicas, as espécies não-albicans estão significativamente emergindo, entre elas $C$. dubliniensis, $C$. glabrata, C. krusei, C. parapsilosis e C. tropicalis (HAZEN, 1995; HAYNES, 2001). A razão para o aumento de casos de candidíase causada por espécies nãoalbicans ainda é obscura. Contudo, a menor sensibilidade dessas espécies aos agentes antifúngicos de uso clínico (COLLIN; CLANCY; NGUYEN, 1999) parece ser parcialmente responsável por esse quadro. Devido a esse fato, a identificação do agente é importante para o planejamento terapêutico e estudos epidemiológicos.

A identificação por métodos convencionais é trabalhosa e requer longo período de tempo. Esses métodos são baseados na micromorfologia das colônias, assimilação de açúcares e testes de fermentação (KURTZMAN; FELL, 1998). Para minimizar o tempo desses procedimentos, vários sistemas comerciais baseados em testes bioquímicos estão disponíveis para identificação presuntiva das diferentes espécies de Candida. Esses métodos evidenciam características fenotípicas, e estas podem sofrer variação entre amostras da mesma espécie.

Vários meios seletivos diferenciais cromogênicos para identificação presuntiva das amostras de Candida foram desenvolvidos (ODDS; BERNAERTS, 1994; COOKE et al., 2002; 
HORVATH et al., 2003; KHAN et al., 2004). Esses meios contêm substratos que reagem com enzimas secretadas pelos fungos produzindo colônias com várias pigmentações. Essas enzimas são espéciesespecíficas, e permitem identificar os microrganismos através da cor e características da colônia.

Com os avanços da biologia molecular, vários métodos moleculares têm sido empregados como ferramenta importante na identificação de Candida sp. Freqüentemente, esses métodos baseiam-se na técnica de amplificação em cadeia pela polimerase, utilizando oligonucleotídeos iniciadores específicos ou randômicos (ERJAVEC; VERWEIJ, 2002).

O objetivo desse estudo foi comparar a utilização do meio cromogênico CHROMagar Candida e a reação de semi-nested PCR (AHMAD et al., 2002) para identificação das espécies de Candida.

\section{Material e Métodos}

\section{Isolados de Candida sp}

Trinta e dois isolados vaginais e vinte isolados de cavidade bucal foram utilizados nesse estudo. As amostras vaginais foram isoladas no Laboratório de Ensino e Pesquisa em Análises Clínicas da Universidade Estadual de Maringá, em 2003. As amostras de cavidade bucal foram isoladas no Centro Integrado de Doenças Infecciosas de Londrina, em 2005. As amostras estavam armazenadas em água destilada a $-20{ }^{\circ} \mathrm{C}$ (McGINNIS; PADHYE; AJELLO, 1974).

As amostras foram cultivadas em ágar Sabouraud (HIMEDIA, Índia) a $37{ }^{\circ} \mathrm{C}$, durante 24 - 48 horas, para análises posteriores. Uma colônia de cada isolado foi inoculada simultaneamente em meio CHROMagar Candida (Probac, Brasil) e caldo Sabouraud e as culturas foram incubadas nas mesmas condições anteriores. As células em meio líquido foram utilizadas para extração de DNA.

A identificação das espécies do gênero Candida no meio cromogênico baseia-se no aspecto e coloração das colônias. Dessa forma, o crescimento de $C$. albicans é caracterizado por colônias lisas e esverdeadas, enquanto $C$. tropicalis apresenta coloração azul e um pigmento púrpura ao redor da colônia. A coloração rosa pode indicar a presença de C. krusei, cujas colônias são grandes e apresentam aspecto rugoso. C. glabrata também produz colônias rosas, entretanto são pequenas e lisas. Outras espécies crescem como colônias brancas, não permitindo a sua identificação.

As amostras de referência incluídas nesse estudo foram fornecidas pela Fundação Instituto Oswaldo Cruz (FIOCRUZ, RJ): C. albicans ATCC 10231, C. parapsilosis ATCC 22019, e C. tropicalis ATCC 28707.

\section{Extração de DNA}

O DNA genômico foi extraído pelo método descrito em Ausubel et al. (1999) com algumas modificações. Resumidamente, os isolados foram cultivados em $3 \mathrm{~mL}$ de meio Sabouraud líquido a 37 ${ }^{\circ} \mathrm{C}$ sob agitação durante 24 horas. As células foram centrifugadas a $10.000 \mathrm{~g}$ e lavadas com água destilada esterilizada. $\mathrm{O}$ sedimento foi ressuspenso em tampão de lise TENTS (10 mM Tris $\mathrm{HCl} \mathrm{pH} 8,0,1 \mathrm{mM}$ EDTA, $100 \mathrm{mM} \mathrm{NaCl} ; 2 \%$ Triton X-100, $1 \%$ SDS), 2 pérolas de vidro $(2 \mathrm{~mm})$ e fenol saturado. A suspensão foi homogeneizada em vórtex três vezes durante 1 minuto cada. $\mathrm{O}$ lisado foi desproteinizado com uma mistura contendo fenol, clorofórmio e álcool isoamílico $(25: 24: 1, \mathrm{v} / \mathrm{v})$. O DNA presente na fase aquosa foi precipitado com etanol absoluto por 2 horas, lavado com etanol 70\% (v/v), seco e ressuspenso com $50 \mu \mathrm{L}$ de água deionizada estéril. O DNA foi tratado com $1 \mu \mathrm{L}$ RNAse $\mathrm{A}(1 \mathrm{mg} / \mathrm{mL})$ a $37^{\circ} \mathrm{C}$ por 1 hora e as concentrações foram estimadas por eletroforese em gel de agarose como descrito em Sambrook e Russel (2001).

\section{Reação de amplificação}

A identificação molecular dos isolados foi realizada por meio da técnica de sn-PCR descrita por Ahmad et al. (2002). Assim, as reações de amplificação de DNA foram realizadas no termociclador Primus 96 Plus (MWGAG Biotech) em volume final de $20 \mu \mathrm{L}$. 
Para o primeiro ciclo de amplificação, foram utilizados $20 \mathrm{mM}$ Tris $\mathrm{HCl} \mathrm{pH} \mathrm{8,4,} 50 \mathrm{mM} \mathrm{KCl,} 2 \mathrm{mM} \mathrm{MgCl}$, $1 \mathrm{U}$ Taq DNA polimerase, 10 pmoles dos iniciadores universais CTSF e CTSR, $1 \mu \mathrm{L}$ do DNA extraído da cultura (cerca de $20 \mathrm{ng}$ ), 0,1 mM dNTPs. Posteriormente, parte do produto dessa reação (cerca de $20 \mathrm{ng}$ ) foi submetida a um segundo ciclo de amplificação, nas mesmas condições, exceto o iniciador CTSF que foi substituído por iniciadores espécies-específicos (CADET, CPDET, CGDET, CTDET). As condições de amplificação para as duas reações consistiram de 1 ciclo de desnaturação a 94 ${ }^{\circ} \mathrm{C}$ por 2 minutos seguidos de 30 ciclos a $94{ }^{\circ} \mathrm{C}$ por 1 minuto, anelamento a $60^{\circ} \mathrm{C}$ por 30 segundos, extensão a $72{ }^{\circ} \mathrm{C}$ por 1 minuto e, finalmente, um ciclo a $72{ }^{\circ} \mathrm{C}$ por 10 minutos. Os produtos de amplificação foram analisados por eletroforese em gel de agarose a 2,5\% como descrito em Sambrook e Russel (2001). Os reagentes utilizados nessa reação foram adquiridos junto a Invitrogen-Gibco (Grand Island, N.Y, USA).

\section{Resultados}

Neste trabalho, a utilização do meio cromogênico permitiu a identificação presuntiva de 39 isolados de leveduras (75\%), enquanto pela técnica molecular foi possível identificar 43 isolados (83\%), em nível de espécie.

No meio cromogênico, os isolados foram identificados presuntivamente como C. albicans (n =22), C. glabrata $(\mathrm{n}=9), C$. tropicalis $(\mathrm{n}=5)$ e $C$. krusei $(\mathrm{n}=3)$. Treze isolados produziram colônias brancas, portanto não puderam ser identificados. Por meio do sn-PCR, os isolados foram identificados como C. albicans $(\mathrm{n}=24), C$. glabrata $(\mathrm{n}=11), C$. tropicalis $(\mathrm{n}=5), C$. parapsilosis $(\mathrm{n}=3)$ e nove isolados não puderam ser identificados. A Figura 1 mostra o perfil dos produtos de amplificação da segunda reação de sn-PCR (com massas moleculares variando aproximadamente, de 100 a 200 pb), de amostras representativas, e a Tabela 1 mostra os resultados obtidos através das duas metodologias.

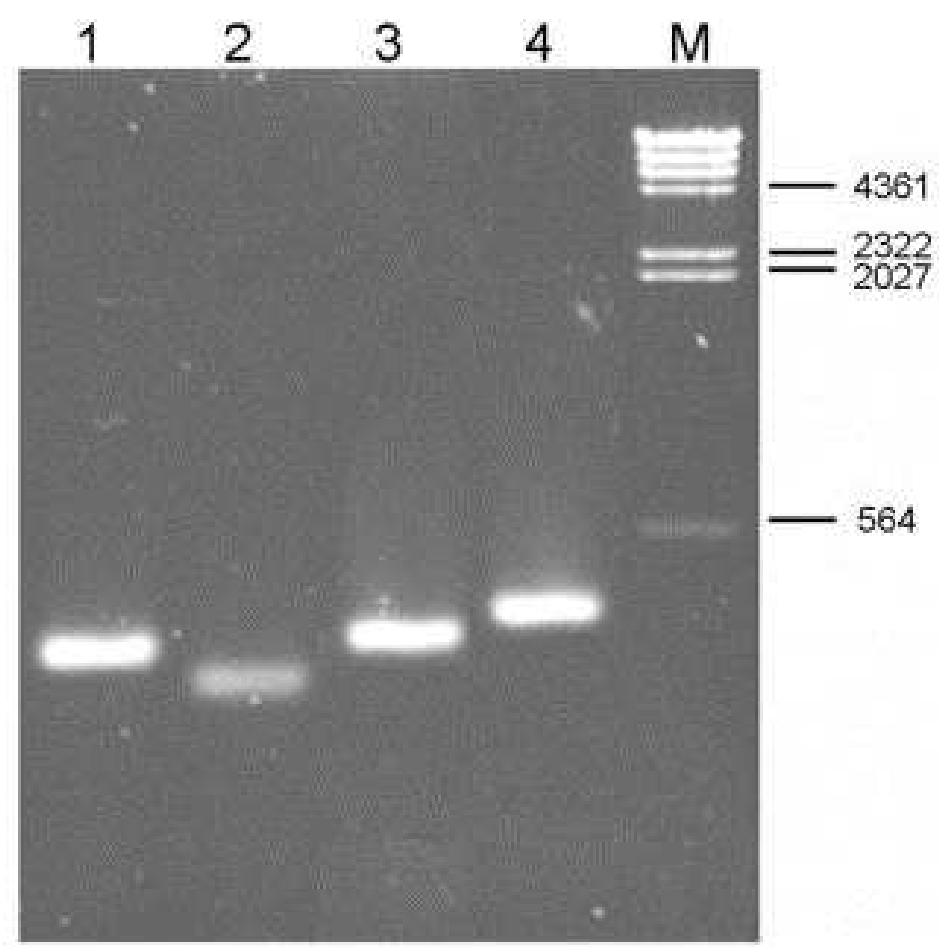

Figura 1. Eletroforese em gel de agarose corado com brometo de etídeo $(0,5 \mu \mathrm{g} / \mathrm{ml})$ dos produtos de amplificação da sn-PCR a partir de DNA genômico de C. albicans (1), C.parapsilosis (2), C. tropicalis (3), e C. glabrata (4). Parte do produto do primeiro ciclo de amplificação foi utilizado para a segunda reação, utilizando-se a combinação dos iniciadores CTSR com CADET, CPDET, CTDET e CGDET, respectivamente. A posição do marcador de massa molecular ( $\lambda$ DNA/Hind III fragments, Invitrogen) está indicada à direita, expresso em pb. 
Tabela 1. Identificação dos isolados clínicos através do meio cromogênico e sn-PCR.

\begin{tabular}{l|c|c|c}
\hline \multirow{2}{*}{ Espécies } & \multicolumn{2}{|c|}{$\begin{array}{c}\text { Número de isolados identificados } \\
\text { por: }\end{array}$} & $\begin{array}{c}\text { \% de concordância } \\
\text { entre os dois métodos }\end{array}$ \\
\cline { 2 - 3 } CHROMagar & sn-PCR & \\
\hline C. glabicans & 22 & 24 & 91,7 \\
\hline C. tropicalis & 09 & 11 & 81,8 \\
\hline C. krusei & 05 & 05 & 100 \\
\hline C. parapsilosis & 03 & NI & - \\
\hline Candida $\mathrm{sp}$ & $\mathrm{NI}$ & 03 & - \\
\hline
\end{tabular}

NI: não identificado

Os resultados positivos do sn-PCR foram concordantes com aqueles obtidos no meio cromogênico para 34 das 52 amostras $(65,4 \%)$. Seis amostras $(11,5 \%)$ não puderam ser identificadas por nenhuma das metodologias empregadas e 12 amostras $(23,1 \%)$ apresentaram resultados discrepantes (Tabela 2). A identificação das amostras de referência foi confirmada pelas duas metodologias.

Tabela 2. Resultados não concordantes obtidos no meio cromogênico e sn-PCR.

\begin{tabular}{l|c|c}
\hline \multicolumn{1}{c|}{ Isolados clínicos } & CHROMagar & sn-PCR \\
\hline FV7, FV21, FV25 & NI & C. albicans \\
\hline FV98 & C. albicans & C. glabrata \\
\hline FV53, FV108 & NI & C. glabrata \\
\hline FV27, FV48 & NI & C. parapsilosis \\
\hline FV103 & C. glabrata & C. parapsilosis \\
\hline CO2, CO34, CO56 & C. krusei & NI \\
\hline
\end{tabular}

FV: amostra isolada de fluidos vaginais; $\mathrm{CO}$ : amostra isolada de cavidade bucal; NI: não identificado

\section{Discussão}

O meio CHROMagar Candida tem sido utilizado para diferenciar, de forma rápida, algumas espécies de Candida a partir de amostras clínicas (ODDS; BERNAERTS, 1994; PFALLER; HOUSTON; COFFMANN, 1996; HORVATH et al., 2003). Cardenes et al. (2004) avaliaram quatro meios cromogênicos comerciais utilizados para identificação de espécies do gênero Candida, entre eles o CHROMagar Candida. Seus resultados mostraram especificidade e sensibilidade maior que $92 \%$ para identificação de C. albicans. Entretanto, esses autores conseguiram identificar apenas 6 dos 108 isolados de $C$. não- albicans $(5,6 \%)$ nesse meio de cultura, diferindo dos nossos resultados onde dezessete amostras $(32,7 \%)$ foram identificadas como espécies $C$. não-albicans.

Dois isolados vaginais foram classificados como espécies diferentes nas duas metodologias. As amostras $98 \mathrm{~V}$ e $103 \mathrm{~V}$ foram identificadas como $C$. albicans e C. glabrata pelo meio cromogênico e 
através do sn-PCR como $C$. glabrata e $C$. parapsilosis, respectivamente. Além disso, três isolados de $C$. albicans e dois de $C$. glabrata não apresentaram perfil característico dessas espécies no meio CHROMagar Candida.

Cooke et al. (2002) compararam vários meios cromogênicos, inclusive o CHROMagar Candida e obtiveram variações nas colorações das colônias entre isolados da mesma espécie. Outros resultados discrepantes entre sistemas comerciais que evidenciam características fenotípicas têm sido descritos na literatura (KOEHLER et al., 1999; MICHEL-NGUYEN et al., 2000; AHMAD et al., 2002). Embora variações fenotípicas intraespécies possam ocorrer, a razão exata para esses resultados ainda é obscura. A identificação presuntiva de $C$. glabrata nesse meio permanece controversa. Alguns autores consideram o uso de CHROMagar apropriado para sua detecção (PFALLER; HOUSTON; COFFMANN, 1996; HOSPENTHAL et al., 2002), enquanto outros não o recomendam (ODDS; BERNAERTS, 1994; KOEHLER et al., 1999; ODDS; DAVIDSON, 2000).

Várias metodologias moleculares para identificação de leveduras do gênero Candida têm sido descritas e muitas utilizam o cluster gênico do RNA ribossomal como alvo (WILLIAMS et al., 1995; PARK et al., 2000; LOEFFLER et al., 2000; FUJTA et al., 2001; GHARIZADEH et al., 2004). Como o gene está presente como múltiplas cópias no genoma dessas leveduras (JONES et al., 2004), as técnicas se tornam altamente sensíveis. Além disso, o tamanho e a sequiência nucleotídica das regiões ITSs (internal transcribed spacer) variam entre as diferentes espécies, o que permite a diferenciação das mesmas.

Na técnica de semi-nested PCR descrita por Ahmad et al. (2002), os oligonucleotídeos iniciadores universais são capazes de amplificar o final da extremidade 3 ' do DNA ribossomal (rDNA) $5.8 \mathrm{~S}$ e a extremidade 5 ' inicial do rDNA $28 \mathrm{~S}$ e a ITS2. No segundo ciclo de amplificação, iniciadores espécieespecíficos complementares à região ITS2 revelam a identidade das espécies. E, ao contrário de muitos métodos, essa técnica não requer manipulação posterior do produto de amplificação. Contudo, a limitação dessa técnica reside no fato de que somente quatro espécies de Candida são identificadas. Dessa forma os isolados de $C$. krusei não puderam ser confirmados através da mesma.

Assim como o meio cromogênico, a reação de sn-PCR pode ser utilizada diretamente em amostras clínicas, tornando mais rápido o processo de identificação das espécies de leveduras (AHMAD et al., 2002).

Os nossos resultados mostram que as duas metodologias podem ser utilizadas para identificação das espécies mais freqüentes de Candida, em laboratórios clínicos. Contudo, novas metodologias capazes de identificar todas as espécies clinicamente importantes devem ser desenvolvidas. A correta identificação das espécies pode contribuir para o estabelecimento de uma terapia mais adequada nos casos de candidíase e conseqüentemente diminuir a freqüência de isolados resistentes aos antifúngicos.

\section{Agradecimentos}

Ao Conselho Nacional de Desenvolvimento Científico e Tecnológico (CNPq), Coordenação de Aperfeiçoamento de Pessoal de Nível Superior (CAPES), e Pro-Reitoria de Pesquisa e Pós Graduação (PROPPG) da Universidade Estadual de Londrina (UEL) pelo apoio financeiro.

\section{Referências}

AHMAD, S.; KHAN, Z.; MUSTAFA, A. S.; KHAN, Z. U. Seminested PCR for diagnosis of candidemia: comparison with culture, antigen detection and biochemical methods for species identification. Journal of Clinical Microbiology, Washington, v.40, n.7, p.2483-2489, 2002.

AUSUBEL, F. M.; BRENT, R.; KINGSTON, R. E.; MOORE, D. D.; SEIDMAN, J. G.; SMITH, J. A.; STRUHL, K. Short protocols in molecular biology. 4. ed. New York: John Wiley and Sons, 1999. 
CALDERONE, R. A.; FONZI, W. A. Virulence factors of Candida albicans. Trends in Microbiology, Cambridge, v.9, n.7, p.327-335, 2001.

CANTÓN, E.; PEMÁN, J.; VIUDES, A.; QUINDÓS, G.; GOBERNADO, M.; ESPINEL-INGROFF, A. Minimum fungicidal concentrations of amphotericin B for bloodstream Candida species. Diagnostic Microbiology and Infectious Disease, New York, v.45, n.3, p.203-206, mar. 2003.

CÁRDENES, C. D.; CARRILLO-MUÑOZ, A. J.; ARIAS, A.; RODRIGUEZ-ALVARES, C.; TORRES-LANA, A.; SIERRA, A.; ARÉVALO, M. P. Comparative evaluation of four commercial tests for presumptive identification of Candida albicans. Journal of Microbiological Methods, Amsterdam, v.59, n.2, p.293-297, nov. 2004.

COLLIN, B.; CLANCY, C. J.; NGUYEN, M. H. Antifungal resistance in non-albicans Candida. Drug Resistance Updates, Edinburgh, v.2, n.1, p.9-14, 1999.

COOKE, V. M.; MILES, R. J.; PRICE, R. G.; MIDGLEY, G.; KHAMRI, W.; RICHARDSON, A. C. New chromogenic agar medium for the identification of Candida spp. Applied and Environmental Microbiology, v.68, n.7, p.3622-3627, 2002.

ERJAVEC, Z.; VERWEIJ, P. E. Recent progress in the diagnosis of fungal infections in the immunocompromised host. Drug Resistance Updates, Edinburgh, v.5, n.1, p.310, 2002.

FUJITA, S. I.; SENDA, Y.; NAKAGUCHI, S.; HASHIMOTO, T. Multiplex PCR using internal transcribed spacer 1 and 2 regions for rapid detection and identification of yeasts strains. Journal of Clinical Microbiology, Washington, v.39, n.10, p.3617-3622, 2001.

GHARIZADEH, B.; NORBERG, E.; LOFFLER, J.; JALAL, S.; TOLLEMAR, J.; EINSELE, H.; KLINGSPOR, L.; NYREN, P. Identification of medically important fungi by the Pyrosequencing ${ }^{\mathrm{TM}}$ technology. Mycoses, Berlin, v.47, n.12, p.29-33, feb. 2004.

HAYNES, K. Virulence in Candida species. Trends in Microbiology, Cambridge, v.9, n.12, p.591-596, 2001.

HAZEN, K. C. New and emerging yeast pathogens. Clinical Microbiology Reviews, Washington, v.8, n.4, p.462-478, 1995.

HORVATH, L. L.; HOSPENTHAL, D. R.; MURRAY, C. K.; DOOLEY, D. P. Direct isolation of Candida spp. from blood cultures on the chromogenic medium CHROMagar Candida. Journal of Clinical Microbiology, Washington, v.41, n.6, p.2629-2632, 2003.

HOSPENTHAL, D. R.; MURRAY, C. K.; BECKIUS, M. L.; GREEN, J. A.; DOOLEY, D. P. Persistence of pigment production by yeast isolates grown on CHROMagar
Candida medium. Journal of Clinical Microbiology, Washington, v.40, n.12, p.4768-4770, 2002.

HUBE, B. From commensal to pathogen: stage- and tissuespecific gene expression of Candida albicans. Current Opinion in Microbiology, Oxford, v.7, n.4, p.336-341, aug. 2004.

JONES, T.; FEDERSPIEL, N. A.; CHIBANA, H.; DUNGAN, J.; KALMAN, S.; MAGEE, B. B.; NEWPORT, G.; THORSTENSON, Y. R.; AGABIAN, N.; MAGEE, P. T.; DAVIS, R. W.; SCHERER, S. The diploid genome sequence of Candida albicans. Proceedings of the National Academic of Sciences of USA, Washington, v.101, n.19, p.7329-7334, 2004.

KHAN, Z. U.; AHMAD, S.; MOKADDAS, E.; CHANDY, R. Tobacco agar, a new medium for differentiating Candida dubliniensis from Candida albicans. Journal of Clinical Microbiology, Washington, v.42, n.10, p.4796-4798, 2004.

KOEHLER, A. P.; CHU, K. C.; HOUANG, E. T. S.; CHENG, A. F. B. Simple, reliable, and cost-effective yeast identification scheme for the clinical laboratory. Journal of Clinical Microbiology, Washington, v.37, n.2, p.422426, 1999.

KURTZMAN, C. P.; FELL, J. W. (Ed.). The yeasts, a taxonomic study. 4.ed. Amsterdam: Elsevier Science B. V., 1998.

LOEFFLER, J.; HEBART, H.; MAGGA, S.; SCHMIDT, D.; KLINGSPOR, L.; TOLLEMAR, J.; SCHUMACHER, U.; EINSELE, H. Identification of rare Candida species and other yeasts by polymerase chain reaction and slot blot hybridization. Diagnostic Microbiology and Infectious Disease, New York, v.38, n.4, p.207-212, 2000.

McGINNIS, M. R.; PADHYE, A. A.; AJELLO, L. Storage os stock cultures of filamentous fungi, yeasts, and some aerobic Actinomycetes in sterile distillide water. Applied Microbiology, Washington, v.28, n.2, p.218-222, 1974.

MATHEMA, B.; CROSS, E.; DUN, E.; PARK, S.; BEDELL, J.; SLADE, B.; WILLIAMS, M.; RILEY, L.; CHATURVEDI, V.; PERLIN, D. S. Prevalence of vaginal colonization by drug-resistant Candida species in college-age women with previous exposure to over-the-counter azole antifungals. Clinical Infectious Diseases, Chicago, v.33, n.5, p.E23-E27, sep. 2001.

MICHEL-NGUYEN, A.; FAVEL, A.; CHASTIN, C.; SELVA, M.; REGLI, P. Comparative evaluation of a commercial identification of Candida lusitaniae. European Journal of Clinical Microbiology and Infectious Diseases, Wiesbaden, v.19, n.5, p.393-395, may 2000.

ODDS, F. C.; BERNAERTS, R. CHROMagar Candida, a new differential isolation medium for presumptive identification of clinically important Candida species. Journal of Clinical Microbiology, Washington, v.32, n.8, p.1923-1929, 1994. 
ODDS, F. C.; DAVIDSON, A. "Room temperature" use of CHROMagar CandidaÔ. Diagnostic Microbiology and Infectious Disease, New York, v.38, n.3, p.147-150, 2000.

PARK, S.; WONG, M.; MARRAS, S. A. E.; CROSS, E. W.; KIEHN, T. E.; CHATURVEDI, V.; TYAGI, S.; PERLIN, D. S. Rapid identification of Candida dubliniensis using a species- specific molecular beacon. Journal of Clinical Microbiology, Washington, v.38, n.8, p.2829-2836, 2000.

PFALLER, M. A.; HOUSTON, A.; COFFMANN, S. Application of CHROMagar Candida for rapid screening of clinical specimens for Candida albicans, Candida tropicalis, Candida krusei, and Candida (Torulopsis) glabrata. Journal of Clinical Microbiology, Washington, v.34, n.1, p.58-61, 1996.

PFALLER, M. A.; JONES, R. N.; DOERN, G. V.; FLUIT, A. C.; VERHOEF, J.; SADER, H. S.; MESSER, S. A.; HOUSTON, A.; COFFMAN, S.; HOLLIS, R. J. International surveillance of bloodstream infections due to Candida species in the European SENTRY Program: species distribution and antifungal susceptibility including the investigational triazole and echinocandin agents. Diagnostic Microbiology and Infectious Disease, New York, v.35, p.19-35, 1999.

PRICE, M. F.; LaROCCO, M. T.; GENTRY,L. O. Fluconazole susceptibilities of Candida species and distribution of species recovered from blood over a 5-year period. Antimicrobial Agents and Chemotherapy, Bethesda, v.38, n.6, p.1422-1424, 1994.
SAMBROOK, J.; RUSSEL, D. W. Molecular cloning: a laboratory manual. 3.ed. New York: Cold Spring Harbor Laboratory, 2001.

SANCHEZ-VARGAS, L. O.; ORTIZ-LOPEZ, N. G.; VILLAR, M.; MORAGUES, M. D.; AGUIRRE, J. M.; CASHATCRUZ, M.; LOPEZ-RIBOT, J. L.; GAITAN-CEPEDA, L. A.; QUINDOS, G. Oral Candida isolates colonizing or infecting human immunodeficiency virus-infected and healthy persons in Mexico. Journal of Clinical Microbiology, Washington, v.43, n.8, p.4159-4162, 2005.

SANT'ANA, P. L.; MILAN, E. P.; MARTINEZ, R.; QUEIROZ-TELLES, F.; FERREIRA, M. S.; ALCANTARA, A. P.; CARVALHO, M. T.; COLOMBO, A. L. Multicenter Brazilian study of oral Candida species isolated from AIDS patients. Memórias do Instituto Oswaldo Cruz, Rio de Janeiro, v.97, n.2, p.253-257, 2002.

WEIG, M.; GROB, U.; MUHLSCHLEGEL, F. Clinical aspects and pathogenesis of Candida infection. Trends in Microbiology, Cambridge, v.6, n.12, p.468-470, 1998.

WILLIAMS, D. W.; WILSON, M. J.; LEWIS, M. A. O.; POTTS, A. J. C. Identification of Candida species by PCR and restriction fragment length polymorphism analysis of intergenic spacer regions of ribosomal DNA. Journal of Clinical Microbiology, Washington, v.33, n.9, p.2476-2479, 1995. 